\title{
Retrospective review of previous minor leak before major subarachnoid hemorrhage diagnosed by MRI as a predictor of occurrence of symptomatic delayed cerebral ischemia
}

\author{
Shinri Oda, MD, ${ }^{1}$ Masami Shimoda, MD, ${ }^{1}$ Akihiro Hirayama, MD, ${ }^{1}$ Masaaki Imai, MD, ${ }^{1}$ \\ Fuminari Komatsu, MD, ${ }^{1}$ Hideaki Shigematsu, MD, ${ }^{1}$ Jun Nishiyama, MD, ${ }^{1}$ Kazuko Hotta, MD, ${ }^{1}$ and \\ Mitsunori Matsumae, MD² \\ 1Department of Neurosurgery, Tokai University Hachioji Hospital, Tokyo; and 2Department of Neurosurgery, Tokai University \\ School of Medicine, Kanagawa, Japan
}

OBJECTIVE This study attempted to determine whether a previous minor leak correlated with the occurrence of symptomatic delayed cerebral ischemia (sDCl).

METHODS The authors retrospectively evaluated sDCl-related clinical features and findings from MRI, including T1weighted imaging (T1WI)-FLAIR mismatch at the time of admission, in 151 patients admitted with subarachnoid hemorrhage (SAH) within 48 hours of ictus.

RESULTS The overall incidence of SDCI was $23 \%$ (35 of 151 patients). In all subjects, multivariate analysis revealed that World Federation of Neurosurgical Societies Grades II-V, age 70 years or older, presence of rebleeding after admission, a previous minor leak before the major SAH attack as diagnosed by T1WI-FLAIR mismatch, acute infarction on diffusion-weighted imaging, and CT SAH score were significantly associated with occurrence of sDCl. In patients with no previous minor leak before major SAH as diagnosed by T1WI-FLAIR mismatch, the incidence of sDCI was only $7 \%$ (7 of 97 patients).

CONCLUSIONS A previous minor leak before major SAH as diagnosed by T1WI-FLAIR mismatch represents an important $\mathrm{SDCl}$-related factor. When the analysis was restricted to patients with true acute $\mathrm{SAH}$ without a previous minor leak diagnosed by T1WI-FLAIR mismatch, the incidence of SDCl was extremely low.

https://thejns.org/doi/abs/10.3171/2016.10.JNS161964

KEY WORDS delayed cerebral ischemia; magnetic resonance imaging; minor leak; subarachnoid hemorrhage; vascular disorders

$\mathrm{I}$ $\mathrm{N}$ patients with aneurysmal subarachnoid hemorrhage (SAH), a preceding minor leak can only be suggested by the presence of a warning headache as disclosed by the patient, family, and/or caregivers during the admission interview. However, poor clinical condition and recall bias can cause inaccuracy. We developed a neuroradiological method to diagnose previous minor leakage before major SAH based on findings from MRI at the time of admission. A previous minor leak before major SAH was determined by the presence of clearly detected bright hyperintense subarachnoid blood (BHSB) on T1-weighted imaging (T1WI) accompanied by SAH blood on FLAIR images distributed over a larger area than BHSB on T1WI (T1WI-FLAIR mismatch). ${ }^{16}$
The development of symptomatic delayed cerebral ischemia (sDCI) after aneurysmal SAH represents the most important complication after SAH and has a major impact on patient outcomes. Several predictors for the occurrence of SDCI have been reported, such as the amount of SAH clot,, 34 clearance of SAH clot, ${ }^{18}$ additional intracerebral hemorrhage (ICH), ${ }^{17}$ and intraventricular hemorrhage. ${ }^{4,11}$ However, the occurrence of sDCI cannot be reliably predicted for the individual patient. We therefore retrospectively reviewed patients with aneurysmal SAH who underwent treatment at our hospital to assess whether MRI findings at the time of admission suggest risk factors for the occurrence of sDCI. This study aimed to assess the association of a previous major leak before major SAH

ABBREVIATIONS BHSB = bright hyperintense subarachnoid blood; DWI = diffusion weighted imaging; ICH = intracerebral hemorrhage; $m R S=$ modified Rankin Scale; $\mathrm{SAH}=$ subarachnoid hemorrhage; $\mathrm{sDCl}=$ symptomatic delayed cerebral ischemia; $\mathrm{T} 1 \mathrm{WI}=\mathrm{T} 1$ - weighted imaging; WFNS = World Federation of Neurosurgical Societies. SUBMITTED July 31, 2016. ACCEPTED October 13, 2016.

INCLUDE WHEN CITING Published online February 10, 2017; DOI: 10.3171/2016.10.JNS161964. 
attack as diagnosed by T1WI-FLAIR mismatch and the occurrence of sDCI, as when experimental SAH-induced vasospasm is induced with the use of a 2-hemorrhage model. ${ }^{14}$ We hypothesized that a previous minor leak has a predictive value for the occurrence of sDCI.

\section{Methods}

\section{Patient Population}

Subjects were selected from the 240 patients in the nontraumatic acute-phase aneurysmal SAH database at our hospital who had been treated between September 2002 and December 2015. Among these patients, we identified 151 patients who had undergone adequate MRI, including diffusion-weighted imaging (DWI), FLAIR imaging, T1WI, and CT on admission and were admitted within 48 hours of SAH onset. Clinical and imaging records were evaluated retrospectively. Study approval was obtained from the institutional review board for clinical research at our university.

\section{Primary End Point}

In principle, the primary end point was the occurrence of sDCI, which was defined as any new ischemic lesion on serial DWI studies or DWI studies obtained at the time of clinical deterioration. Similarly, when new infarction attributable to SDCI was not confirmed on DWI, we defined the apparent angiographic vasospasm at the time of clinical deterioration as sDCI.

\section{Imaging Protocol}

Patients with aneurysmal SAH routinely undergo serial MRI on admission, within 2-7 days after surgery, and before discharge. In addition, MRI was used for diagnosis of cerebral infarction due to sDCI at the time of clinical deterioration. At all time points, serial MRI included axial conventional T1WI, FLAIR, DWI, and MR angiography and was performed using a 1.5-T superconducting magnet (Signa EXCITE or HDX, GE Medical Systems) with a quadrature head coil. Pulse sequences were collected according to our previously reported parameters. ${ }^{16}$

All patients underwent 3D CT angiography to identify ruptured aneurysms and estimate early vasospasm of major vessels. MRI was performed only after obtaining informed consent from the patient and/or a relative. Initial MRI at the time of admission was performed before conventional angiographic, surgical, or endovascular procedures in all cases.

\section{Surgical Procedure and Patient Management}

Patients with SAH in the acute stage underwent craniotomy or intravascular surgery within 72 hours after SAH onset. With the exception of patients with Fisher Grade 1 or $2 \mathrm{SAH}$ based on CT findings at the time of admission, indicating no or only a small hematoma, all patients underwent cisternal or lumbar drainage. All patients were administered fasudil hydrochloride intravenously for 7-21 days postoperatively as prophylaxis against sDCI. The 100 most recent patients also received oral cilostazol $(200 \mathrm{mg} /$ day) for 7-21 days postoperatively. Hypervolemic therapy was administered according to previously reported protocols. ${ }^{20}$

\section{Definitions of Variables}

All patients were graded on admission according to the World Federation of Neurosurgical Societies (WFNS) grading system. ${ }^{2}$ SAH severity was classified using CT findings according to the Fisher grading system. ${ }^{3} \mathrm{SAH}$ observed on CT was scored semiquantitatively according to the methods outlined previously ${ }^{8}$ as the sum of scores ranging from 0 to 3 for each of 10 cisterns: 0 , no blood; 1, small amount of blood in SAH; 2, moderate amount of blood in SAH; and 3, SAH completely filled with blood. We added analysis of bilateral convex sulci, so a total of 12 cisterns were investigated (CT SAH score). These scores were totaled to create an SAH sum score ranging from 0 to 36 .

Warning headache was defined as a sudden and unusually severe headache lasting at least 1 hour, followed by a symptom-free interval or marked improvement of symptoms before admission for major SAH. The presence of a warning headache was identified in thorough admission interviews of patients and their relatives or accompanying individuals.

Among patients with T1WI-detected clear BHSB on admission MRI, if the distribution of SAH on T1WI (T1WI BHSB component) almost entirely matched the distribution of SAH on FLAIR (FLAIR hyperintense component), the patient was diagnosed with subacute SAH that was not associated with rebleeding ${ }^{16}$ and was thus excluded from the study. In the remaining patients with T1WIdetected BHSB, the distribution of subarachnoid blood on FLAIR images over a larger area than the BHSB on T1WI (T1WI-FLAIR mismatch) was taken as an indication of new, acute SAH. T1WI-detected BHSB in these patients represents subacute $\mathrm{SAH}$ due to a previous minor leak. ${ }^{16}$ If FLAIR-detected SAH had no T1WI-detected BHSB on admission MRI, the SAH was considered acute.

On the admission MRI study, high-intensity lesions visible on DWI that showed low signal intensity in the lesion on apparent diffusion coefficient mapping were defined as DWI-detected early infarction at the time of SAH onset. ${ }^{19}$

Diagnosis of ICH was defined as a collection of blood more than $1 \mathrm{~cm}$ in diameter detected by CT. Rebleeding after admission was defined as a definite increase in the volume of blood visible on CT accompanied by sudden deterioration of the level of consciousness compared with baseline MRI or CT findings on admission.

In principle, sDCI was defined as clinical deterioration with new infarction detected by DWI (serial DWI or DWI at the time of deterioration). Even if a patient with clinical deterioration did not exhibit new cerebral infarction on DWI, we diagnosed sDCI when distinct angiographic vasospasm was evident on neuroradiological images. Clinical deterioration caused by sDCI was defined as a new neurological deterioration that included focal deficit, decline in level of consciousness, or either transient or permanent motor paresis. A decreased level of consciousness was defined as a $\geq 2$-point decrease in the Glasgow Coma Scale score within a 24 -hour period. ${ }^{23}$ For the detection of 


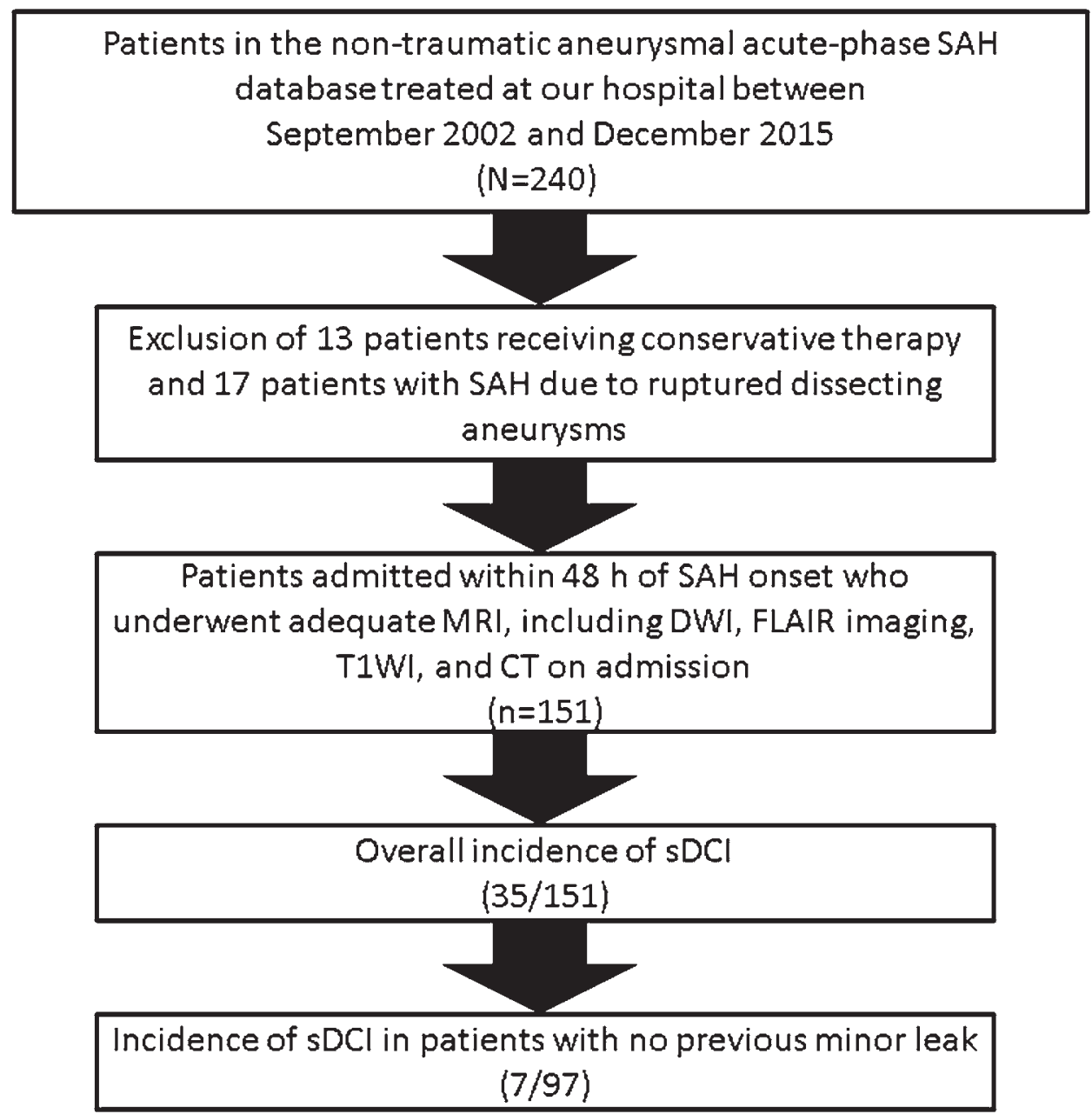

FIG. 1. Flow diagram of patient selection. $h=$ hours.

vasospasm, transcranial Doppler ultrasonography was not routinely performed. Instead, all patients who experienced clinical deterioration underwent 3D CT angiography or conventional digital subtraction angiography to determine the presence of vasospasm and rule out other causes of deterioration (e.g., hydrocephalus, rebleeding, cerebral edema, seizure, infection, or metabolic disturbance). ${ }^{22,23}$ Based on findings on immediate postoperative CT, serial MRI, or MRI at the time of clinical deterioration, infarction after SAH accompanied by SDCI was distinguished from lesions of primary brain damage that had occurred at the time of aneurysm rupture or surgery-related complications, such as contusion, local brain edema caused by retraction,,$^{10}$ or infarction due to occlusion of parent arteries or perforators after aneurysm clipping or coiling.

CT and MRI findings were interpreted by at least 2 senior stroke neurosurgeons (M.S. and S.O., with 33 and 28 years of experience, respectively). In the case of disagreement between raters, the diagnosis was determined by consensus decision.

Outcome was assessed at 3 months using the modified Rankin Scale (mRS). ${ }^{21}$ Patients were stratified into favorable outcome (mRS Scores 0-2) or unfavorable outcome (mRS Scores 3-6). Postoperative management was conducted in accordance with previously reported protocols. ${ }^{19,20}$

\section{Statistical Analysis}

Clinical factors potentially associated with occurrence of sDCI were analyzed using Fisher's exact test for categorical variables and an independent sample 2-tailed Student t-test for continuous variables (age, CT SAH score). All clinical factors with a significance level of $\mathrm{p}<0.05$ by univariate analysis were subjected to multivariate logistic regression analysis, with occurrence of sDCI as the dependent variable. Statistical analyses were performed using SPSS for Windows version 22.0 (IBM).

\section{Results}

\section{Participants}

Among the 240 patients treated between September 2002 and December 2015, we excluded 13 who received conservative therapy instead of surgery due to the absence of brainstem reflexes and 17 with $\mathrm{SAH}$ due to ruptured dissecting aneurysms (Fig. 1). The remaining 210 patients underwent acute-stage aneurysm surgery via craniotomy 
TABLE 1. Clinical features and neurological status on admission

\begin{tabular}{|c|c|c|c|c|}
\hline \multirow[b]{2}{*}{ Variable } & \multirow[b]{2}{*}{ Total } & \multicolumn{2}{|c|}{ Value* $^{*}$} & \multirow{2}{*}{$\begin{array}{c}p \\
\text { Value }\end{array}$} \\
\hline & & $\mathrm{w} / \mathrm{sDCl}$ & w/o sDCl & \\
\hline No. of patients & 151 & $35(23)$ & $116(77)$ & \\
\hline \multicolumn{5}{|l|}{ Warning sign } \\
\hline Yes & 15 & $2(6)$ & $13(11)$ & 0.523 \\
\hline No & 62 & $4(11)$ & $58(50)$ & $<0.001$ \\
\hline Unknown & 74 & $29(83)$ & $45(39)$ & $<0.001$ \\
\hline \multicolumn{5}{|l|}{ Age (yrs) } \\
\hline Mean \pm SD & $61 \pm 14$ & $67 \pm 13$ & $60 \pm 14$ & 0.008 \\
\hline Range & $21-89$ & $42-86$ & $21-89$ & \\
\hline$\geq 70$ yrs & 48 & $19(54)$ & $29(25)$ & 0.002 \\
\hline Female sex & 106 & $28(80)$ & $78(67)$ & 0.206 \\
\hline Rebleeding after admission & 32 & $15(43)$ & $17(15)$ & 0.001 \\
\hline \multicolumn{5}{|l|}{ WFNS grade on admission } \\
\hline 1 & 90 & $9(26)$ & $81(70)$ & $<0.001$ \\
\hline$\|-\mathrm{V}$ & 61 & $26(74)$ & $35(30)$ & $<0.001$ \\
\hline IV \& V & 32 & $15(43)$ & $17(15)$ & 0.001 \\
\hline
\end{tabular}

* Values represent number (\%) unless stated otherwise. Percentages in the "no. of patients" row are based on the total number of patients, and the remaining percentages in the " $\mathrm{w} / \mathrm{sDCl}$ " and "w/o sDCl" columns are based on the number of patients with and without $\mathrm{SDCl}$, respectively.

or an interventional procedure within 72 hours of SAH onset. Among these 210 patients, we identified 151 patients admitted within 48 hours of SAH onset who underwent adequate MRI, including DWI, FLAIR, T1WI, and CT on admission. These 151 SAH patients showed stable vital signs, reflecting adequate respiration and circulation, and they underwent serial MRI and CT after admission.

\section{Outcome Data}

The overall incidence of sDCI was $23.2 \%$ (35 of 151 patients) (Table 1).

\section{Main Results}

Symptomatic DCl, Clinical Features, and Neurological Status

Table 1 summarizes the preoperative clinical features that differed significantly between patients with and without sDCI. The incidence of sDCI was significantly higher in elderly SAH patients ( $\geq 70$ years old) and patients with disturbance of consciousness (WFNS Grade II-V) or rebleeding after admission.

The incidence of warning headache was low (10\%) and was not associated with occurrence of sDCI. The incidence of sDCI was significantly lower among the 62 patients (41\%) who reported no history of warning headache before admission. Among the 74 patients (49\%) in whom the presence or absence of warning headache was unknown, the incidence of sDCI was significantly higher (Table 1).

\section{Symptomatic $\mathrm{DCl}$ and Neuroradiological Features on Admission}

Table 2 summarizes the neuroradiological features on admission that differed significantly between patients with and without sDCI. The incidence of SDCI was significantly
TABLE 2. CT and MRI features on admission

\begin{tabular}{|c|c|c|c|c|}
\hline \multirow[b]{2}{*}{ Variable } & \multirow[b]{2}{*}{ Total } & \multicolumn{2}{|c|}{ Value } & \multirow[b]{2}{*}{$\begin{array}{c}\mathrm{p} \\
\text { Value }\end{array}$} \\
\hline & & $\begin{array}{c}\mathrm{w} / \\
\mathrm{sDCl}\end{array}$ & $\begin{array}{l}w / 0 \\
\mathrm{sDCl}\end{array}$ & \\
\hline No. of patients & 151 & $35(23)$ & $116(77)$ & \\
\hline \multicolumn{5}{|l|}{ CT findings } \\
\hline Fisher Grade 3 & 107 & $33(94)$ & $74(64)$ & $<0.001$ \\
\hline CT SAH score, mean \pm SD & $17 \pm 10$ & $26 \pm 7$ & $14 \pm 10$ & $<0.001$ \\
\hline $\mathrm{ICH}$ & 30 & $12(34)$ & $18(16)$ & 0.027 \\
\hline Intraventricular hemorrhage & 78 & $29(83)$ & $49(42)$ & $<0.001$ \\
\hline \multicolumn{5}{|l|}{ MRI findings } \\
\hline Acute hydrocephalus & 78 & $31(89)$ & $47(41)$ & $<0.001$ \\
\hline T1WI-FLAIR mismatch & 54 & $28(80)$ & $26(22)$ & $<0.001$ \\
\hline Acute infarction on DWI & 16 & $11(34)$ & $5(4)$ & $<0.001$ \\
\hline Periventricular WML & 37 & $17(49)$ & $20(17)$ & 0.001 \\
\hline Deep WML & 62 & $21(60)$ & $41(35)$ & 0.011 \\
\hline Old infarction & 24 & $11(31)$ & $23(20)$ & 0.006 \\
\hline $\begin{array}{l}\text { DWI-detected SAH on } \\
\text { basal cistern }\end{array}$ & 99 & $33(94)$ & $66(57)$ & $<0.001$ \\
\hline $\begin{array}{l}\text { DWI-detected SAH on con- } \\
\text { vexity }\end{array}$ & 54 & $26(74)$ & $28(24)$ & $<0.001$ \\
\hline DBS on FLAIR & 50 & $26(74)$ & $28(24)$ & $<0.001$ \\
\hline \multicolumn{5}{|l|}{ Aneurysm site } \\
\hline $\begin{array}{l}\text { Anterior communicating } \\
\text { artery }\end{array}$ & 48 & $15(43)$ & $33(28)$ & \\
\hline Anterior cerebral artery & 8 & $1(3)$ & $7(6)$ & \\
\hline Internal carotid artery & 50 & $10(29)$ & $40(35)$ & \\
\hline Middle cerebral artery & 34 & $7(20)$ & $27(23)$ & \\
\hline Posterior circulation & 11 & $1(3)$ & $10(7)$ & 0.458 \\
\hline \multicolumn{5}{|l|}{ Aneurysm size } \\
\hline$\geq 5 \mathrm{~mm}$ & 86 & $19(54)$ & $67(58)$ & 0.846 \\
\hline$\geq 10 \mathrm{~mm}$ & 11 & $4(11)$ & $7(6)$ & 0.283 \\
\hline
\end{tabular}

DBS = diffuse brain swelling; $W M L=$ white matter lesion.

Values represent number (\%) unless stated otherwise. Percentages in the "no. of patients" row are based on the total number of patients, and the remaining percentages in the " $\mathrm{w} / \mathrm{sDCl}$ " and "w/o sDCl" columns are based on the number of patients with and without $\mathrm{sDCl}$, respectively.

higher in patients with T1WI-FLAIR mismatch. Among 54 patients with T1WI-FLAIR mismatch, 24 were $\geq 70$ years old. Among these elderly patients, 16 had sDCI.

\section{Symptomatic DCl, Surgery, and Subsequent Events}

Table 3 summarizes the surgery and subsequent events that were significantly different between patients with and without sDCI. In 2 sDCI patients without delayed angiographic vasospasm, new cerebral infarction was confirmed on serial DWI. In 2 additional sDCI patients, although new infarction attributable to sDCI was not confirmed on serial DWI or DWI at the time of neurological deterioration, apparent angiographic vasospasm was identified. Conversely, 10 patients displayed new asymptomatic infarction on serial DWI and were not classified as showing sDCI.

Among patients with chronic hydrocephalus and poor 
TABLE 3. Drug administration, surgery, and subsequent events

\begin{tabular}{|c|c|c|c|c|}
\hline \multirow[b]{2}{*}{ Variable } & \multirow[b]{2}{*}{ Total } & \multicolumn{2}{|c|}{ No. of Patients } & \multirow{2}{*}{$\begin{array}{c}p \\
\text { Value }\end{array}$} \\
\hline & & $\mathrm{w} / \mathrm{sDCl}$ & w/o sDCl & \\
\hline No. of patients & 151 & $35(23)$ & $116(77)$ & \\
\hline \multicolumn{5}{|l|}{ Aneurysm surgery } \\
\hline Craniotomy & 122 & $28(80)$ & $94(81)$ & 1.000 \\
\hline Coiling & 29 & $7(20)$ & $22(19)$ & \\
\hline Administration of cilostazol & 100 & $25(71)$ & $75(65)$ & 0.543 \\
\hline Delayed angiographic vasospasm & 49 & $33(94)$ & $16(14)$ & $<0.001$ \\
\hline New infarction on serial DWI & 43 & $33(94)$ & $10(9)$ & $<0.001$ \\
\hline Chronic hydrocephalus* & 69 & $26(74)$ & $43(37)$ & $<0.001$ \\
\hline $\mathrm{mRS}$ Score $3-6$ at 3 mos & 52 & $29(83)$ & $23(20)$ & $<0.001$ \\
\hline
\end{tabular}

Values represent number (\%) unless stated otherwise. Percentages in the "no. of patients" row are based on the total number of patients, and the remaining percentages in the "w/ sDCl" and "w/o sDCl" columns are based on the number of patients with and without $\mathrm{SDCl}$, respectively.

* The incidence of chronic hydrocephalus was calculated for surviving patients.

prognosis (mRS Scores 3-6), the incidence of sDCI was significantly higher.

\section{Clinical Factors Predicting sDCl in Multivariate Analysis}

In all subjects, multivariate stepwise logistic regression analysis revealed that WFNS Grades II-V, age $\geq 70$ years, and presence of rebleeding after admission as preoperative clinical factors, and T1WI-FLAIR mismatch, acute infarction on DWI, and CT SAH score as neuroradiological findings on admission were significantly associated with the occurrence of sDCI (Table 4).

\section{Incidence of $\mathrm{sDCl}$ in Patients With No Previous Minor Leak Before Major SAH}

Overall, in 97 of the 151 patients admitted within 48 hours of SAH onset who underwent adequate neuroradiological imaging, T1WI-FLAIR mismatch was not observed. Among these patients, the incidence of sDCI was only $7 \%$ (7 of 97 patients).

\section{Discussion}

\section{Key Results}

Symptomatic $\mathrm{DCl}$ and Neuroradiological Diagnosis of a Minor Leak Prior to Major Attack

Disclosure of a previous minor leak during the admission interview is known to often be inaccurate, as eliciting complete information from a patient in poor clinical condition is difficult. ${ }^{9}$ Unsurprisingly then, in our study, occurrence of sDCI did not correlate with the disclosure of a previous minor leak before major SAH. In contrast, a neuroradiologically diagnosed minor leak prior to major SAH using T1WI-FLAIR mismatch correlated significantly with the occurrence of SDCI as determined by multivariate analysis.

One possible reason for the significant correlation between SDCI and a previous minor leak would be the time lag between the onset of a minor leak and presentation to a hospital. Strictly speaking, at the time of admission due to major $\mathrm{SAH}, \mathrm{SAH}$ patients with a previous minor leak
TABLE 4. Results of multivariate logistic regression analysis for the presence of a symptomatic delayed cerebral ischemia

\begin{tabular}{crcr}
\hline \multicolumn{1}{c}{ Variable } & OR & $95 \% \mathrm{Cl}$ & $\mathrm{p} \mathrm{Value}$ \\
\hline Preop clinical factors & & & \\
\hline WFNS Grades II-V & 4.898 & $1.992-12.046$ & 0.001 \\
\hline Age $\geq 70$ yrs & 2.725 & $1.149-6.452$ & 0.023 \\
\hline Rebleeding after admission & 2.571 & $1.010-6.536$ & 0.047 \\
\hline $\begin{array}{c}\text { Associated neuroradiological } \\
\text { findings on admission }\end{array}$ & & & \\
\hline T1WI/FLAIR mismatch & 41.667 & $9.524-200$ & $<0.001$ \\
\hline Acute infarction on DWI & 9.259 & $1.876-45.455$ & 0.006 \\
\hline CT SAH score & 1.221 & $1.117-1.337$ & $<0.001$ \\
\hline
\end{tabular}

diagnosed by T1WI-FLAIR mismatch corresponded to a clinical group in the subacute phase. As a matter of course, initiation of prophylaxis for sDCI such as administration of fasudil hydrochloride and/or cilostazol, as validated management strategies for maintaining systemic euvolemia, is delayed in these patients. Furthermore, a previous minor leak before a major SAH attack will mean that obstruction of the subarachnoid space by the presence of blood, fibrin, and fibrous arachnoid adhesions will interfere with clearance of the SAH clot. This decreased clearance of the SAH clot will in turn facilitate the occurrence of sDCI. ${ }^{18}$

Patients who experience a minor leak prior to major SAH are experiencing rebleeding at the time of the major SAH. Experimental models have shown that rebleeding increases the incidence of vasospasm; $;^{14,25}$ however, little information is available regarding the complications of rebleeding, including effects on the development of sDCI in humans. Lord et al. reported that rebleeding after SAH is not associated with changes in the incidence of $\mathrm{SDCI} ;{ }^{13}$ however, the definition of SDCI used by Lord et al. was the presence of either symptomatic vasospasm or infarction on CT attributable to vasospasm. This definition of sDCI seems prone to inaccuracy, because evaluation of infarction accompanied by sDCI is difficult in the presence of additional brain damage after rebleeding identified on CT. Diagnosis of clinical deterioration due to SDCI is likewise difficult in the presence of poor neurological condition due to rebleeding. For patients with rebleeding, we consider DWI as necessary for a suitably accurate diagnosis of cerebral infarction accompanied by sDCI. In the results from the present study, in addition to a significant correlation between the occurrence of sDCI and a minor leak prior to major SAH as diagnosed by T1WIFLAIR mismatch, rebleeding after admission also correlated significantly with the occurrence of sDCI. Our previous report ${ }^{16}$ and several past investigations ${ }^{1,6}$ identified a previous minor leak as a risk factor for rebleeding after admission because a fragile aneurysm that ruptured at the time of the minor leak will be prone to rebleeding. As a matter of course, the volume of SAH clot is increased in patients who experience rebleeding. Moreover, rebleeding after admission and a minor leak prior to the major SAH reportedly correlate with the occurrence of ICH. ${ }^{6,15,16}$ Both the volume of SAH $\operatorname{clot}^{3,24}$ and additional $\mathrm{ICH}^{17}$ are predictors of sDCI that have been reported. 


\section{Other sDCl-Related Clinical Factors}

The relationship of age to the occurrence of sDCI remains controversial, and no definitive conclusions have yet

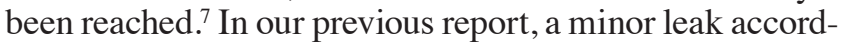
ing to T1WI-FLAIR mismatch was significantly correlated with elderly SAH patients on multivariate analysis. ${ }^{16}$ We speculate that symptoms due to a minor leak would be milder in elderly patients than in younger SAH patients, because an increase in intracranial pressure may not occur even after aneurysmal rupture due to the age-associated enlargement of the subarachnoid space. Therefore, elderly SAH patients presenting to the hospital at the time of the first attack due to a minor leak could be relatively few, and they may often be brought to the hospital only following major SAH. ${ }^{16}$ As a result, we considered that significant sDCI may be more frequent among the elderly.

Fisher Grade 3 SAH was significantly associated with sDCI on univariate analysis but not on multivariate analysis. The resolution of CT scanning has greatly improved since the first publication of the Fisher scale, and thus detection of subarachnoid clots has also dramatically improved, and differentiation between Grades 2 and 3 has thus become difficult. In addition, the amount of SAH as determined by Fisher grade is gradually losing significance as a predictive factor for sDCI. On the other hand, a more quantitative method for calculating SAH score correlated significantly with the occurrence of SDCI on multivariate analysis.

The concept of early brain injury, referring to the immediate cerebral damage that occurs within the first 72 hours after SAH, has recently been suggested. ${ }^{12}$ Early brain injury is a multifactorial process characterized by primary insults and secondary ischemia. Primary insults involve factors such as the rapid increase in intracranial pressure, decreased global cerebral blood flow, disruption of the blood-brain barrier, brain swelling, and cerebral microcirculatory disturbance. ${ }^{5}$ In our study, WFNS Grade II-V and acute infarction on $\mathrm{DWI}^{19}$ also correlated significantly with the occurrence of sDCI. While these clinical factors are among the indicators of primary insults involved in early brain injury after SAH, clarification of their relevance requires further clinical studies.

\section{Limitations}

In this report, we could not prove whether a previous hemorrhage as apparent on MRI really represents a minor leak. We therefore should have used the term "preceding rupture" rather than "minor leak."

We routinely performed CT immediately postoperatively and serial MRI at admission and within 2-7 days of surgery. However, completely distinguishing sDCI-associated infarction from infarction due to aneurysm repair is difficult because artifacts from clips or coils are present to some extent.

Because nimodipine has not been approved for use as a calcium-channel antagonist for the prevention of sDCI in Japan, we were unable to administer this drug. Therefore, our results may not apply to stroke centers where nimodipine is used.

This was a retrospective, single-center study; these findings therefore require prospective validation in depen- dent cohorts before valid application in clinical practice can be considered.

\section{Conclusions}

A previous minor leak before major SAH as diagnosed by T1WI-FLAIR mismatch is an important sDCI-related factor. The incidence of sDCI was extremely low in patients with true acute SAH without a previous minor leak diagnosed by T1WI-FLAIR mismatch. Past studies of sDCI may have included both patients with pure acute SAH without a previous minor leak and SAH patients with a previous minor leak before SAH major attack.

Given the retrospective nature of this study and the fact that all patients were from a single center, prospective validation of the present findings in dependent cohorts is required before the findings can be generalized to the general patient population.

\section{References}

1. Beck J, Raabe A, Szelenyi A, Berkefeld J, Gerlach R, Setzer $\mathrm{M}$, et al: Sentinel headache and the risk of rebleeding after aneurysmal subarachnoid hemorrhage. Stroke 37:2733-2737, 2006

2. Drake CG: Report of World Federation of Neurological Surgeons Committee on a universal subarachnoid hemorrhage grading scale. J Neurosurg 68:985-986, 1988

3. Fisher CM, Kistler JP, Davis JM: Relation of cerebral vasospasm to subarachnoid hemorrhage visualized by computerized tomographic scanning. Neurosurgery 6:1-9, 1980

4. Frontera JA, Claassen J, Schmidt JM, Wartenberg KE, Temes $\mathrm{R}$, Connolly ES Jr, et al: Prediction of symptomatic vasospasm after subarachnoid hemorrhage: the modified fisher scale. Neurosurgery 59:21-27, 2006

5. Fujii M, Yan J, Rolland WB, Soejima Y, Caner B, Zhang JH: Early brain injury, an evolving frontier in subarachnoid hemorrhage research. Transl Stroke Res 4:432-446, 2013

6. Güresir E, Beck J, Vatter H, Setzer M, Gerlach R, Seifert V, et al: Subarachnoid hemorrhage and intracerebral hematoma: incidence, prognostic factors, and outcome. Neurosurgery 63:1088-1094, 2008

7. Harrod CG, Bendok BR, Batjer HH: Prediction of cerebral vasospasm in patients presenting with aneurysmal subarachnoid hemorrhage: a review. Neurosurgery 56:633-654, 2005

8. Hijdra A, Brouwers PJ, Vermeulen M, van Gijn J: Grading the amount of blood on computed tomograms after subarachnoid hemorrhage. Stroke 21:1156-1161, 1990

9. Jakobsson KE, Säveland H, Hillman J, Edner G, Zygmunt S, Brandt L, et al: Warning leak and management outcome in aneurysmal subarachnoid hemorrhage. J Neurosurg 85:995999, 1996

10. Kivisaari RP, Salonen O, Ohman J: Basal brain injury in aneurysm surgery. Neurosurgery 46:1070-1076, 2000

11. Kramer AH, Hehir M, Nathan B, Gress D, Dumont AS, Kassell NF, et al: A comparison of 3 radiographic scales for the prediction of delayed ischemia and prognosis following subarachnoid hemorrhage. J Neurosurg 109:199-207, 2008

12. Kusaka G, Ishikawa M, Nanda A, Granger DN, Zhang JH: Signaling pathways for early brain injury after subarachnoid hemorrhage. J Cereb Blood Flow Metab 24:916-925, 2004

13. Lord AS, Fernandez L, Schmidt JM, Mayer SA, Claassen J, Lee K, et al: Effect of rebleeding on the course and incidence of vasospasm after subarachnoid hemorrhage. Neurology 78:31-37, 2012

14. Megyesi JF, Vollrath B, Cook DA, Findlay JM: In vivo ani- 
mal models of cerebral vasospasm: a review. Neurosurgery 46:448-461, 2000

15. Naidech AM, Janjua N, Kreiter KT, Ostapkovich ND, Fitzsimmons BF, Parra A, et al: Predictors and impact of aneurysm rebleeding after subarachnoid hemorrhage. Arch Neurol 62:410-416, 2005

16. Oda S, Shimoda M, Hirayama A, Imai M, Komatsu F, Shigematsu $\mathrm{H}$, et al: Neuroradiologic diagnosis of minor leak prior to major SAH: diagnosis by T1-FLAIR mismatch. AJNR Am J Neuroradiol 36:1616-1622, 2015

17. Platz J, Güresir E, Wagner M, Seifert V, Konczalla J: Increased risk of delayed cerebral ischemia in subarachnoid hemorrhage patients with additional intracerebral hematoma. J Neurosurg [epub ahead of print March 11, 2016. DOI: 10.3171/2015.12.JNS151563]

18. Reilly C, Amidei C, Tolentino J, Jahromi BS, Macdonald RL: Clot volume and clearance rate as independent predictors of vasospasm after aneurysmal subarachnoid hemorrhage. J Neurosurg 101:255-261, 2004

19. Shimoda M, Hoshikawa K, Shiramizu H, Oda S, Yoshiyama M, Osada T, et al: Early infarction detected by diffusionweighted imaging in patients with subarachnoid hemorrhage. Acta Neurochir (Wien) 152:1197-1205, 2010

20. Shimoda M, Oda S, Tsugane R, Sato O: Intracranial complications of hypervolemic therapy in patients with a delayed ischemic deficit attributed to vasospasm. J Neurosurg 78:423-429, 1993

21. Shinohara Y, Minematsu K, Amano T, Ohashi Y: Modified Rankin scale with expanded guidance scheme and interview questionnaire: interrater agreement and reproducibility of assessment. Cerebrovasc Dis 21:271-278, 2006

22. Shirao S, Yoneda H, Ishihara H, Kajiwara K, Suzuki M: A proposed definition of symptomatic vasospasm based on treatment of cerebral vasospasm after subarachnoid hemorrhage in Japan: Consensus 2009, a project of the 25 Spasm Symposium. Surg Neurol Int 2:74, 2011

23. Vergouwen MD, Vermeulen M, van Gijn J, Rinkel GJ, Wijdicks EF, Muizelaar JP, et al: Definition of delayed cerebral ischemia after aneurysmal subarachnoid hemorrhage as an outcome event in clinical trials and observational studies: proposal of a multidisciplinary research group. Stroke 41:2391-2395, 2010

24. Weir B, Macdonald RL, Stoodley M: Etiology of cerebral vasospasm. Acta Neurochir Suppl 72:27-46, 1999

25. Zabramski JM, Spetzler RF, Bonstelle C: Chronic cerebral vasospasm: effect of volume and timing of hemorrhage in a canine model. Neurosurgery 18:1-6, 1986

\section{Disclosures}

The authors report no conflict of interest concerning the materials or methods used in this study or the findings specified in this paper.

\section{Author Contributions}

Conception and design: Shimoda, Oda, Matsumae. Acquisition of data: all authors. Analysis and interpretation of data: Shimoda, Oda, Matsumae.

\section{Correspondence}

Masami Shimoda, Department of Neurosurgery, Tokai University Hachioji Hospital, 1838 Ishikawa-machi, Hachioji, Tokyo 1920032, Japan. email: mashimoda-nsu@umin.ac.jp. 